International Journal of Current Advanced Research

ISSN: O: 2319-6475, ISSN: P: 2319 - 6505, Impact Factor: SJIF: 5.995

Available Online at www.journalijcar.org

Volume 6; Issue 4; April 2017; Page No. 3079-3081

DOI: http://dx.doi.org/10.24327/ijcar.2017.3081.0186

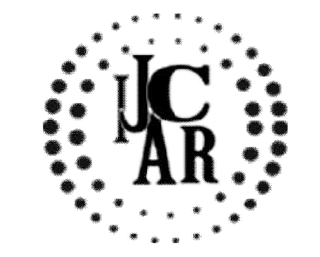

Research Article

\title{
EFFECTS OF AMLA ON CONSTIPATION
}

\author{
Ditty J Mary* and Gayathri Devi
}

Saveetha Dental College and Hospitals, Chennai 77

\begin{tabular}{l}
\hline A R T I C L E I N F O \\
\hline Article History: \\
Received $11^{\text {th }}$ January, 2017 \\
Received in revised form $19^{\text {th }}$ February, 2017 \\
Accepted $22^{\text {nd }}$ March, 2017 \\
Published online $28^{\text {th }}$ April, 2017 \\
\hline
\end{tabular}

Key words:

Amla, Constipation,

Digestion, Antioxident

\begin{abstract}
A B S T R A C T
Amla is considered to be one of the most important plants in Ayurveda.It has many therapeutic benefits.Constipation is a condition in which there is difficulty in emptying the bowels, usually associated with hardened faces. Amla being a natural remedy for Constipation, has been used in this experiments to study the effects on constipation. Constipation is a condition in which there is difficulty in emptying the bowels, usually associated with hardened faces. Amla due to its strong antioxidant and biologicalproperties prevent innumerable health disorders as it contains essential nutrients and highest amount of vitamin C.This herb is a very powerful antioxidant, preventing damage from free radicals that cause cell oxidation. Antioxidants are important for antiaging and preventing diseases such as cancer, diabetes and heart disease. Due to the fact that amalaki or amla contains high amount of fiber it promotes regular bowel movements. It is also beneficial for reducing stress. Amla also helps works well for inflammation, improve fertility, strengthen the lungs and boost the immune system. It is also considered an exfoliating and astringent agent. Regular use will make the skin look younger and make it tighter. Amla is good for strong bones, teeth and nails, as it helps the body absorb calcium.
\end{abstract}

Copyright $(2017$ Ditty J Mary and Gayathri Devi. This is an open access article distributed under the Creative Commons Attribution License, which permits unrestricted use, distribution, and reproduction in any medium, provided the original work is properly cited.

\section{INTRODUCTION}

Amla known as amalaki or the Indian gooseberry is a nutrient rich fruit whose benefits for health have been established and reaped since ancient times. ${ }^{[1]}$ Amla is one of the most often used herbs in Indian ayurveda. Indian gooseberry comprises of the following nutrients: dietary fiber, vitamin C, calcium, Phosphorus, Iron, Carotene, Vitamin B complex, Protein, and Carbohydrates. Indian gooseberry has also been found to be low in saturated fats, cholesterol and sodium, making it good for health. ${ }^{[2]}$ Only few quality controlled clinical trials are documented despite the widespread use of emblica in traditional health systems. Uses of amla include the following: Anti-inflammatory Effects. Antimicrobial Effects. Anti Cancer effects Hypolipidemic effects, anti diabetes effects, and antioxidative effect. ${ }^{[2]}$ Amla in spite of all these effects it is unarguably a good natural remedy for constipation. ${ }^{[3]}$

Popularly used in inks shampoos and hair oils, the high tannin content of Indian gooseberry fruit serves as a mordant for fixing dyes in fabrics. Amla shampoos and hair oil are traditionally believed to nourish the hair and scalp and prevent premature grey hair.In kerala well beds are lined with Emblica timber to get clean and sweet water for drinking and cooking. ${ }^{[6]}$

*Corresponding author: Ditty J Mary

Saveetha Dental College and Hospitals, Chennai 77
A human pilot study demonstrated a reduction of blood cholesterol levels in both normal and hypercholesterolemic men with treatment. ${ }^{[7]}$ The irregular and infrequent evacuation of the bowels is known as constipation. This problem is cures by taken of 1 teaspoon of amla powder with milk or water every morning. On the other hand 4 tea spoon of fresh amla juice and 3 teaspoon of honey mixed with water may deal this constipation. If constipation is caused by parasites, take $20 \mathrm{gms}$ of fresh amla juice every day may destroy the worms. ${ }^{[8]}$

According to Ayurveda, amla balances all three doshas. While amla is unusual in that it contains five out of the six tastes recognized by Ayurveda, it is the most important to recognize the effects of the potency, and post-digestive effect. ${ }^{[6]}$

\section{Uses of Amla}

One reason for amla's reputation as a general energypromoting, disease-preventing tonic may be its effect on the immune system. Multiple studies have shown significant increases in white blood cell counts, and other measures of strengthened immunity in rodents given amla. ${ }^{[10]}$ Indian gooseberry is beneficial in the treatment of respiratory disorders. It is especially valuable in tuberculosis of lungs asthma and bronchitis ${ }^{[11]}$. This herb, due to its high Vitamin $\mathrm{C}$ content, is effective in controlling diabetes. A tablespoon of its juice mixed with a cup of bitter gourd juice, taken daily for 2 months will stimulate the pancreas and enable is to secrete insulin, thus reducing the blood sugar in diabetes. Diet 
restrictions should be strictly observed while taking this medicine. It will also prevent eye complication in diabetes. ${ }^{[12]}$ Indian gooseberry is considered an effective remedy for heart disease. It tones up the functions of all the organs of the body and builds up health by destroying the heterogeneous or harmful and disease causes elements. It also renews energy. ${ }^{[10]}$ The juice of Indian gooseberry with honey is useful in preserving eyesight. It is beneficial in the treatment of conjunctivitis and glaucoma. It reduces infra ocular tension in a remarkable manner. Juice mixed with honey can be taken twice daily for this condition. ${ }^{[13]}$

Indian gooseberry has revitalizing effects, as it contains an element which is very valuable in preventing ageing and in maintaining strength in old age. It improves body resistance and protects the body against infection. It strengthens the heart, hair, and different gland in the body. ${ }^{[11]}$ Amla is rich in vitamin $\mathrm{c}$ which is very important in the absorption of iron which helps the people suffering from anemia. ${ }^{[14]}$ Amla is rich in Vitamin $\mathrm{C}$ and helps control blood pressure.. Triphala, a combination of amla and two other herbs is an excellent medication for high blood pressure. ${ }^{[11]} \mathrm{Amla}$ is the most concentrated form of Vitamin $\mathrm{C}$ found in the plant kingdom, and when the whole fruit is used rather than an active ingredient, the Vitamin $\mathrm{C}$ is easily assimilated by the human body. ${ }^{[15]}$

\section{Other uses}

- In treatment of scurvy ${ }^{[15]}$

- Useful in treatment of mouth ulcers ${ }^{[16]}$

- Balances stomach acids ${ }^{[11]}$

- Enhances food absorption ${ }^{[16]}$

- Nourishes the brain and mental functioning ${ }^{[17]}$

- Helps the urinary system ${ }^{[17]}$

- Good for the skin ${ }^{[16]}$

- Promotes healthier hair ${ }^{[11]}$

- Diarrhoea ${ }^{[11]}$

- Act as a body coolant $t^{[16]}$

A normal pattern of stool evacuation is thought to be a sign of health in children all ages. Especially during the first months of life, parents pay close attention, frequency and characteristics of their children's defecation. Any deviation from what is thought by any family member to be normal for children may trigger a call to the nurse or a visit to the paediatrician. Thus, it is not surprising that approximately $3 \%$ of general paediatric outpatient visits and $25 \%$ of paediatric gastroenterology consultations are related to a perceived defecation disorder. ${ }^{[4]}$. Chronic constipation is a source of anxiety for parents who worry that a serious disease may be causing the symptom. Yet, only a small minority of children have an organic cause for constipation. Beyond the neonatal period, the most common cause of constipation is functional and has been called idiopathic constipation, functional fecal retention, and fecal withholding. ${ }^{[4]}$

Most cases of constipation respond to conservative treatment, such as dietary and exercise changes or mild laxatives. Doctors will usually start treatment by recommending more fiber or bulk in your diet. Except for fiber or bulking agents, over-the-counter laxatives should be avoided. Doctors also encourage to take adequate time for moving your bowels and not to suppress the urge to have bowel. Movement increasing exercises are also important if leading a sedentary lifestyle. ${ }^{[5]}$ For stubborn constipation in older children or adults, the doctor may recommend a non-digestible sugar called lactulose specially formulated electrolyte solutions. Polyethylene glycol (Miral AX) is available in the counter for short-term use in constipation for children and adults. Lubriprostone amitizia linaclotide (Linzess) are prescription for drugs longterm use in chronic constipation in adults.Fecal impaction is a more serious form of constipation that sometimes affects the elderly and disabled. To release hardened material in the rectum, a doctor inserts a gloved finger and manually breaks up the solidified stool. A gentle enema using warm water or mineral oil may also be helpful. ${ }^{[5]}$

In this article I am going to discuss about the effects of Amla on constipation and how it can be used to treat constipation.

\section{METHODOLOGY}

A detailed study was carried out on people who were suffering from constipation. Sample size of the study was 20 people.And was divided into two groups experimental group and standard group. Out of which 10 people were experimental group $(\mathrm{N}=10)$ and 10 were sample group $(\mathrm{N}=10)$. The experimental group of 20 people were givena medium sized fresh Amla (approximately 35g) on a daily basis for 2 weeks.The Amla was procured from the local vegetable market in the Chennai city.They were asked to consume the fruit in raw state daily at night before dinner.During the course of supplementation no modification in the diet or medication was made for both experimental and control groups.

\section{RESULT}

There were more significant changes on the experimental group of 10 peoplewhen it was given with one glass of water.In this study a very good result was seen on the experimental group of people. Before eating Amla 4 out of 10 had staining, 5 out of 10 had rectal bleeding 3 had rectal prolapse and 9 had pain during passing of stools. But after eating amla a significant changes was noted on the 10 people only 1 out of 10 had staining, only 2 had rectal bleeding 2 had rectal prolapse and only one had pain.

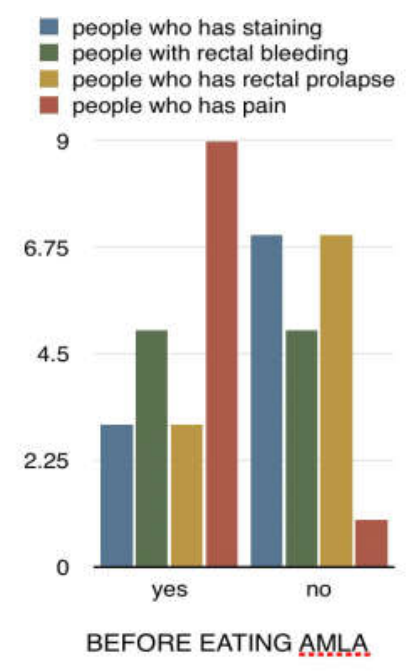


From this we can conclude that Amla has a significant and positive effect on constipation.
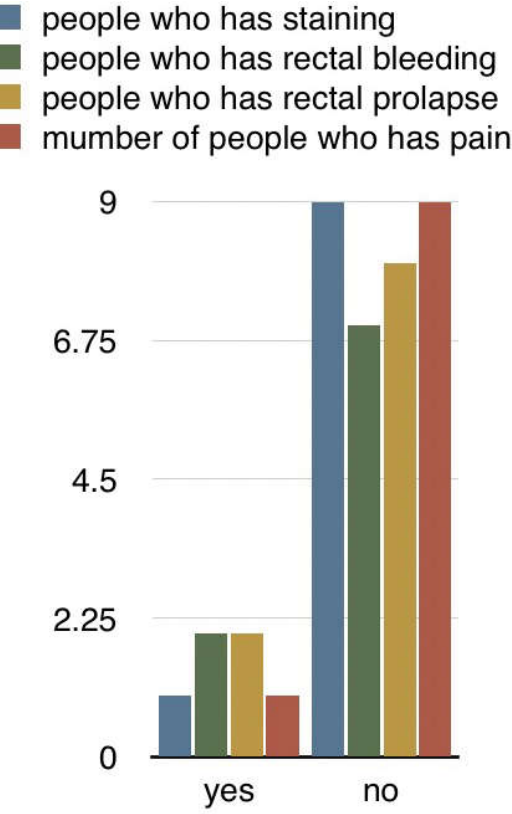

After eating Amla

\section{DISCUSSION}

Amla helps in digestion by reducing constipation. The fruit is high in fibre and helps in regularising bowel movement. It also helps in the absorption of nutrients. A drink made with Amla and lemon helps in reducing constipationGiven the tendency of people towards traditional medicine and using, the findings of this study indicate that the use of the Amla along with a glass of water seems to be an effective, inexpensive and safe treatment for constipation management. ${ }^{(19)} \mathrm{A}$ powder of Amla seed is given along with red sandalwood and honey to prevent constipation.In this study it is proven that taking Amla along with a glass of water is also a good remedy for constipation. ${ }^{(12)}$ Fresh green leaves of amla is crushed and mixed with curd taken before food can improves good digestion and reduces constipation. From all these we can understand that Amla is unarguably a good natural remedy for constipation My study has proven very clearly from the improvement on the constipated people that amla when taken with one glass of water daily it can reduce constipation and can show a good result on constipation. Several researchers revealed that various extracts and herbal formulations of amla showed potential therapeutic benefits against various diseases and the results are similar to standard drugs. In this research, we tried to make a summary the traditional and scientifically proven uses of amla and tried to establish their basic mechanisms.

\section{CONCLUSION}

Amla has a greater significant effect on constipation. Amla is unarguably a good natural remedy for constipation. Amla supplemented group showed a favorable impact on constipation of the subjects in this study. This could be due to the nutrient and photochemical composition of Amla. The fruit Amla is the richest source of vitamin C, containing more than 20 times that of orange. The gallotannins in the fruit preserve the vitamins under all conditions. Even though, amla has various medicinal properties since ages, there is a colossal necessity to scientifically explore and evident its medicinal values at molecular level with help of various latest biotechnological tools and techniques.

\section{Reference}

1. Www.google.com

2. (INDIAN GOOSEBERRY): An ancient food supplement. MB Kavitha , Malika KJ M.B Kavita et al/ IJRAP 4(1) Jan-Feb 2013

3. Effects of amla on various physiological and biochemical parameters of metabolic syndrome Dr. Manoj Gupta, Kamlesh Chandra Mathur, Kavitha Yadav, Pooja Sharma Scholars journal of applied medical science (SJAMS)

4. Constipation in infants and children evaluation and treatment Baker Susan, liptak, Gregory's collecti, Richard B, Groffey Joseph

5. www.Webmd.com

6. www.wikipedia.com

7. Jacob A, Pandey M, Kapoor S, Saroja R (Nov 1988). "Effect of the Indian gooseberry (amla) on serum cholesterol levels in men aged 35-55 years". Eur J Clin Nutr. 42 (11): 939-443. PMID 3250870.

8. Thakur RS, Puri HS, Husain, Akhtar. Major Medicinal Plants of India. Central Institute of Medicinal and Aromatic Plants, Lucknow, 1989.

9. Aman zulkarnain, Dr Quarrathulrin, Mrs. Salma Ain, editors "non leafy vegetables" Dr medicinal secrets of your food.Mysore: Indo American Hospital Trust; 1996 P.395-400.

10. Bhandari PR, Kamdod MA. Emblica officinalis (Amla): A review of potential therapeuticapplications. Int J Green Pharm 2012; 6:257-69.

11. Therapeutic effects of Amla in medicine and dentistry.A review Harpreet Singh Grover, Himanshu Deswal, Yogender Singh, Amit Bhardwarj.

12. Khan KH. Roles of Emblica officinalis in medicine - A review. Bot Res Int 2009; 2:218-28.

13. Nisha P, Singhal RS, Pandit AB. A study on degradation kinetics of ascorbic acid in amla (Phyllanthus emblica L.) during cooking. Int J Food Sci Nutr 2004; 55:415-22.

14. Kumar KP, Bhowmik D, Dutta A, Yadav AP, Paswan S, Srivastava $\mathrm{S}$, et al. Recent trends in potential traditional Indian herbs Emblica officinalis and its medicinal importance. J Pharmacogn Phytochem 2012; 1:18-28.

15. Gopalan C, Sastri BV, Balasubramaniam SC. Nutritive Value of Indian Foods. Hyderabad, India: NIN; 1991.

16. Singh E, Sharma S, Pareek A, Dwivedi J, Yadav S, Sharma S. Phytochemistry, traditional uses and cancer chemopreventive activity of Amla (Phyllanthus emblica): The sustainer. J Appl Pharm Sci 2011; 2:176-83.

17. Reddy VD, Padmavathi P, Kavitha G, Gopi S, Varadacharyulu N. Emblica officinalis ameliorates alcohol-induced brain mitochondrial dysfunction in rats. $J$ Med Food 2011; 14:62-8.

18. Swetha Dasaroju*, Krishna Mohan Gottumukkala Centre for Pharmaceutical Sciences (CPS), Institute of Scienceand Technology (IST), Jawaharlal Nehru Technological University- Hyderabad (JNTUH), Andhra Pradesh, India.

19. Amla: A novel Ayurvedic herb as o functional food for health benefits. A small review, Mirunalini, Velusamy, and mani Krishnaveni. 